\title{
Build better seniors' care: new CMA head
}

$\mathrm{C}$ anada needs a seniors' care strategy that celebrates the "triumph of aging," urged new Canadian Medical Association President Dr. Chris Simpson at the close of the organization's annual meeting in Ottawa.

"Our failure to change to meet our seniors' needs impacts every single component of the health care system," he told attendees in his inaugural address. "Our system doesn't deliver the quality that it should. It doesn't deliver the timeliness that it should. And it doesn't deliver the value for money that it should."

Canada was a younger, healthier nation when Tommy Douglas and the other architects of universal health care laid the foundation of our current system in the 1960s, explained Simpson. Today, $15 \%$ of Canadians are 65 or older and more people of all ages have chronic diseases requiring long-term management.

"Unfortunately, our health care system has not changed to meet the needs presented by this new reality," said Simpson. The upshot: overcrowded hospitals, long wait times and ballooning costs.

For example, the "warehousing of seniors in hospital beds" wastes some $\$ 2.3$ billion each year that could be invested in cheaper models of care tailored to seniors' needs.

"A patient in a hospital bed costs the system about $\$ 1000$ a day," explained Simpson. In comparison, long-term care costs about $\$ 130$ a day; home care, about $\$ 55$ a day. "It is time all levels of

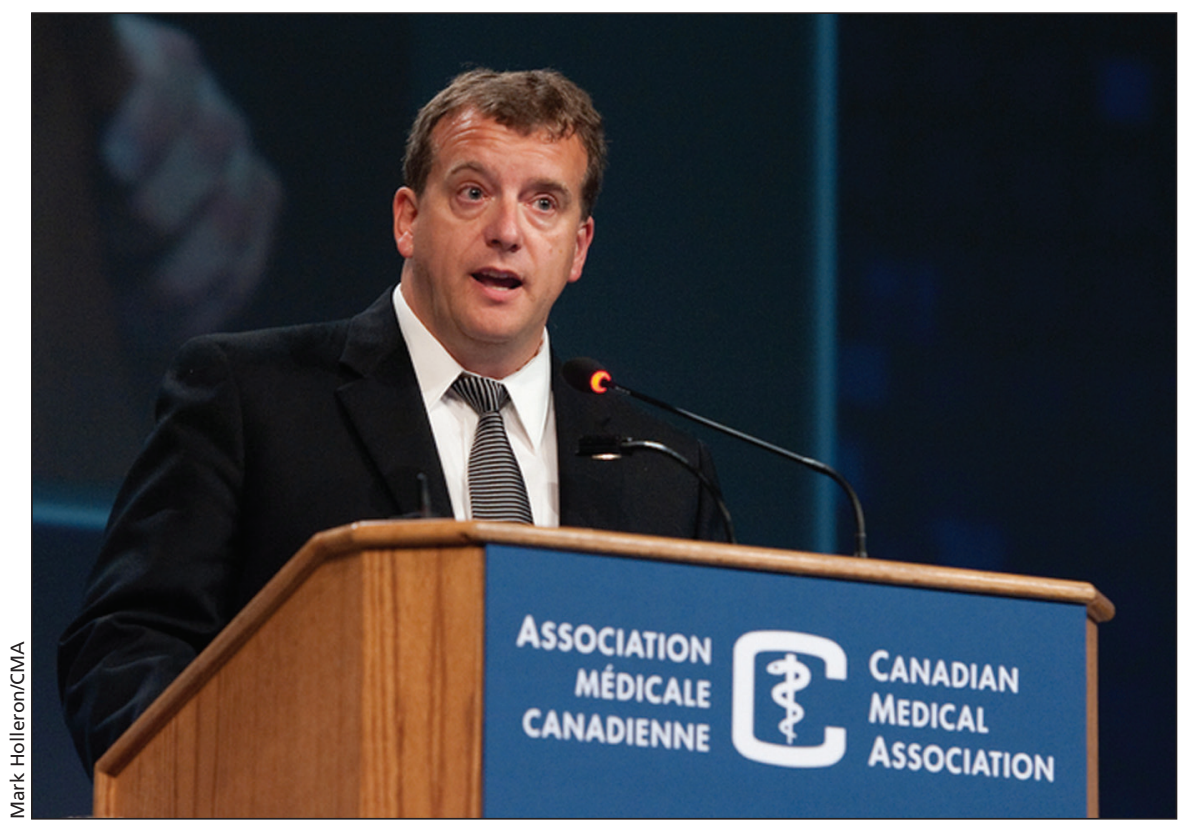

Seniors' care is the paramount health care issue of our time, says the new Canadian Medical Association President Dr. Chris Simpson.

government do the math and spend smarter."

Canada can look to top-performing health systems across the Atlantic for inspiration. In two decades, Denmark has closed thousands of hospital beds and avoided adding new long-term care beds by investing strategically in home and community services.

A robust Canadian strategy must also address the social determinants of health, access to preventive and primary care including house calls, support for informal caregivers, and access to palliative care, said Simpson. "It comes down to long-range planning and strategic investment.'

International experience also shows that a "committed federal government is a necessary ingredient for success," he said. Canadians are "tired of excuses as to why the federal government can't take action."

A recent survey of voters in swing ridings showed that almost $60 \%$ would switch political parties if their current party failed to make seniors a priority in the next federal election campaign.

"The building and maintenance of a healthy Canada is the responsibility of every level of government," urged Simpson, "And federal leadership has never been needed more." - Lauren Vogel, CMAJ

CMAJ 2014. DOI:10.1503/cmaj.109-4883 